\title{
Performance Analysis of Increased Safety HT Induction Motor with Higher Stator Coil Pitch for Classified Hazardous Area
}

\author{
Bhagirath Ahirwal $^{1}$, Tarun Kumar Chatterjee ${ }^{2}$ \\ ${ }^{1}$ Flame \& Explosion Lab., CSIR-Central Institute of Mining \& Fuel Research, Barwa Road, Dhanbad, (JH)- \\ 826015, India, Phone: +91-326-2296025, +91-326-2296003, Fax: +91-326-2296019 \\ ${ }^{2}$ Electrical Engineering Department, Indian School of Mines, Dhanbad, (JH)-826001, India \\ Phone: +91-326-2235437, Fax: +91-326-2296563 \\ E-mail: ahirwalcmri@yahoo.co.uk,tkcism@yahoo.com
}

\begin{abstract}
The increased safety (Ex e) high tension (HT) motors are widely used in the petroleum industries and area where explosive atmosphere is present. The time $t_{E}$ and $I_{A} / I_{N}$ ratio value is very important for Ex $e$ motor. The time $t_{E}$ of rotor and or stator winding, $I_{A} / I_{N}$ ratio and temperature rise can be affected by increasing the stator coil pitch. The coil pitch of stator were increased for three different ratings of three phase HT Ex e induction motors and redesigned for analyzing the temperature rise, $t_{E}$ and performance. The relevant tests were performed and performance characteristic of motor was compared with normal design motor. The Ex e motors mentioned in this paper had been manufactured by Bharat Heavy Electricals Ltd. (BHEL), Bhopal, India during the project as per the design and guidance of main author as project leader. It is anticipated that the research work presented in this paper will be of immense benefit to Ex e HT motor designers.
\end{abstract}

Keywords: Increased safety motor, stator coil profile, time $t_{E}, I_{A} I_{N}$ ratio, temperature rise

\section{Introduction}

The increased safety concept is a form of "built in" protection in that the equipment is specially built to prevent it from becoming a source of ignition and this protection intends for safe use in Zone 1 and less hazardous area. Increased safety protection method is widely being used for junction boxes and motors for safe operation in zone 1 and 2 hazardous area but in India it is applicable for use in zone 2 area only as per IS 5571 [1]. The increased safety protection is a type of explosive protection method where, the apparatus does not produce spark, arc or become excessively hot in normal operating condition and specified abnormal condition. Ex e motor is in which additional measures are applied, so as to give increased security against possibility of excessive temperatures and occurrence of arcs or sparks in apparatus which under normal circumstances do not produce any arc or spark. The specific measures are applied to electrical apparatus to avoid ignition of a surrounding explosive atmospheres [2]. The Ex e motor should sustain normal and specified abnormal condition, therefore, the protection depends upon the length of time $t_{E}$ for which such a situation can exist prior to the protective devices operating. The Ex e motor is dependent mainly on the temperature rise of insulation of winding, $I_{A} / I_{N}$ ratio and time $t_{E}$ with respect to safety of hazardous area.

The essential principle of electrical apparatus with increased safety concept is:

i) The internal and the external surface temperature of any part of motor should not exceed the ignition temperature of the surrounding gases under any circumstance where motor is to be installed.

ii) Time $t_{E}$ : is the time taken by $A C$ windings to reach the limiting temperature of winding insulation at rated operating conditions during starting or stalling. This time ' $\mathrm{E}_{\mathrm{E}}$ ' should not be less than 5 seconds as per IS/IEC 60079-7 [3].

iii) $I_{A} / I_{N}$ ratio: it is the ratio of the starting current $\left(I_{A}\right)$ to rated full load current $\left(I_{N}\right)$ of Ex e motor.

It has been reviewed that during normal operating conditions, the induction machine produces synchronously rotating useful air gap field. However, the current in the stator end winding, produces stray field components. These components together with leakage 
components due to stator core magnetic saturation induce circulating current to flow in any closed conducting circuits. The current causes arcs and sparking at the joints of a multi-section motor enclosure $[4,5]$. The stray end winding field will be the strongest during locked rotor and starting conditions. Sparking may also occur across the air gap due to the movement of the bars due centrifugal and electromagnetic influences. Sparking generally occurs during the starting condition $[4,5]$. Corona discharges and surface tracking [6] on contaminated winding can also cause sparking. The phenomenon of sparking and arcing could pose a hazard in explosive atmosphere [7]. When three-phase induction and synchronous motors are properly designed, built, installed, and maintained, uncontained sparking is not expected except at higher speeds and higher voltages [8]. The level, when higher voltages and higher speeds, induce sparking varies greatly with the design [9]. The stator sparking can occur at any time during motor operation. The risk is increased by transients from the network, surface contamination and ageing. Rotor sparking results from the intermittent breaking of the contact between the rotor bars and core. It occurs during starting only, and is limited to the first sections of the rotor core. Manufacturers can prevent rotor sparking by taking steps during design and production to ensure that the rotor bars are properly locked. In some cases the bars are swaged into the slot for this purpose [10]. The rotor and stator type tests are required to prove that machines are not even able to ignite an explosive gas atmosphere inside of them [11]. The stator winding of HT motor shall be designed to assess for permissible breakdown impulse voltage in explosive gas mixture without failure of stator winding [12].

The temperature rise of a motor can vary due to losses i.e core loss, copper loss during normal operation and overload condition of the motor, high starting current, stalling current, loading conditions. The occurrence of spark/arc inside the motor is generally happened due to failure of winding insulation which can be controlled by proper designing of the motor as per the loading condition and duty cycle. The temperature rise depends on the inter-relationship between heating and cooling cycle of insulation material of winding. Under steady-state conditions, the final temperature rise is reached when the rates of production and dissipation of heat are equal. Generally Ex e motors are designed with $I_{A} / I_{N}$ ratio of 5 to 7 and time $t_{E}$ of 6 to 8 seconds which is some time more stringent from safety point of view. The objective of the present research work to minimize the $I_{A} / I_{N}$ ratio and increasing the time $t_{E}$ by proper designing of Ex e motor so that motor will take more time to attend the maximum temperature limit of machine. If stator coil pitch (the distance between the two sides of an individual coil of winding) of motor is increased then effective number of turns increases causing increase of reactance and hence starting current will decrease which will reduce $I_{A} / l_{N}$ ratio and increase time $t_{E}[13]$.

The paper describes the design aspect and performance characteristics of normal Ex e HT induction motors rated $810 \mathrm{KW} / 6.6 \mathrm{KV} / 16$ pole/ 3Phase/ $50 \mathrm{~Hz}, 970 \mathrm{KW} / 6.6 \mathrm{KV} / 18$ pole/ $3 \mathrm{Phase} / 50 \mathrm{~Hz}$ and $2200 \mathrm{KW} / 6.6 \mathrm{KV} / 2$ pole/ $3 \mathrm{Phase} / 50 \mathrm{~Hz}$ (designated as Normal motors). These three HT Ex e motors were the requirement of the user hence these motors are chosen to study for the performance analysis with increase in stator coil pitch. The risk factors for these motors are more than six. The risk assessment factors require input from an end user and they were beyond the control of the motor manufacturer [14]-[15]. The performance of same Ex e HT induction motors have been studied and compared the data after designing the motors with increase in stator coil pitch in the same frame size by keeping the external surface area of the motor constant.

During the design of the increased safety motors, the safety features as defined in IS/IEC 60079-7 standard were considered [16]. The safety features of these motors are:

- No arc or sparks in normal operation including starting and locked rotor.

- No hot spots above the temperature class special enclosure protection - dust tight and water tight (IP55).

- Special insulating materials/system to withstand ignition spark assessment.

- Larger than normal creepage and clearance distances between connecting terminals.

\section{Design of Normal Increased Safety HT Ex e Motor}

A normal increased safety HT motor is designed keeping in view that the time $t_{E}$ should not be less than the specified time limit. The time $t_{E}$ and $I_{A} / I_{N}$ ratio is very important parameters of Ex e HT motors on which safety depends. The $I_{A} / I_{N}$ ratio shall not be more than 10 [3]. The time $t_{E}$ of rotor winding of increased safety motor depends on the different parameters like mass of rotor bar, specific heat of winding material, heat dissipation factor and rotor copper loss or 
starting torque of motor. The time $t_{E}$ of increased safety motor can be increased either by reducing starting current and or change in coil pitch [13]. The objective of this paper is to find out the effect of increased stator pitch on the time $t_{E}, I_{A} / I_{N}$ ratio, temperature rise and performance of motor by keeping the frame size and other ratings of the motor same. The $810 \mathrm{KW}$ and $970 \mathrm{KW}$ motors are low speed motors and $2200 \mathrm{KW}$ motor is high speed. The creepage distance and clearance between connecting terminals of the main power supply and other low voltage supply is maintained same in normal motor and increased stator coil pitch motor and these values are more than the specified value of IS/IEC 60079-7.

As we know that $\Delta \theta / \mathrm{t}_{\mathrm{E}}=\mathrm{b} \times \mathrm{I}^{2} \mathrm{R} / \mathrm{m} \times \mathrm{s}[17]$ and $\mathrm{I}^{2} \mathrm{R}=$ Starting torque $\times \mathrm{KW}$ rating of motor, so heat balance equation can be written as

$$
\Delta \Theta / t_{E}=b \times \text { Starting torque } \times \mathrm{KW} \text { rating of motor } / \mathrm{m} \times \mathrm{s}
$$

where, $\mathrm{m}=$ mass of cage winding, $\mathrm{s}=$ specific heat of copper, $\mathrm{b}=$ ventilation factor, $I^{2} \mathrm{R}=$ copper loss in rotor winding, $\Delta \theta=$ temperature difference and $\mathrm{t}_{\mathrm{E}}=$ time.

If $\mathrm{s}, \Delta \theta, \mathrm{m}, \mathrm{b}$ and $\mathrm{KW}$ rating of motor are constant for a particular motor design, so Eq. (1) can be written as $t_{E} \alpha 1 /$ Starting torque i.e. time $t_{E}$ is inversely proportional to starting torque of the motor. The stator coil pitch of motor is increased then effective number of turns increases causing increase of reactance and hence starting current will decrease. If the starting current decreases so starting torque of motor is also decreased. Hence, time $t_{E}$ of motor may be increased by decreasing the starting torque of motor upto optimization limit by increasing the coil pitch of stator.

The Ex e squirrel cage induction motors of rating $810 \mathrm{KW}, 970 \mathrm{KW}$ and $2200 \mathrm{KW}$ are designed and the same motors with increased in stator coil pitch of motor are also further designed.

\section{Design of Stator Core of Ex e Motor}

\subsection{Stator Core}

The stator core consists of laminated circular varnished punching made of cold rolled non grain oriented and finally annealed silicon sheet $(0.65 \mathrm{~mm}$ thick) steel and insulated with each other by a $7 \pm 1.5$ micron thick layer of Stabolit-40 varnish on both sides. The specific loss at flux density of $1.5 \mathrm{~Wb} / \mathrm{M}^{2}$ is $3.5 \mathrm{Watt} / \mathrm{Kg}$ for high tensile sheet steel with a stacking factor of $95.5 \%$ and segmental punching are used.

\subsection{Stator Core Length}

Generally, for a particular number of poles, each frame size has at least 4 - 5 combinations of core lengths (gross and net) for different kW output. Thus core length value of each Ex e motor under discussion is given in the Table 3. The selection of number of radial ventilating ducts, for a particular core length is done on the basis of ventilation circuit calculations. The ventilation duct width is normally kept $8 \mathrm{~mm}$ for all above mentioned motors.

\subsection{Stator Slot Profile}

The shape of slot has an important effect on the operating performance of the motor as well as on the method of insulation of stator coils. However for these Ex e HT motors, open type stator slots are used because with this the coils can be formed and insulated properly before housing in the slots. The open slots also give best power factor due to lower leakage reactance. A typical open type stator slot profile is used for these Ex e motors as is shown in Figure 1 and given dimensions are in millimeter. 


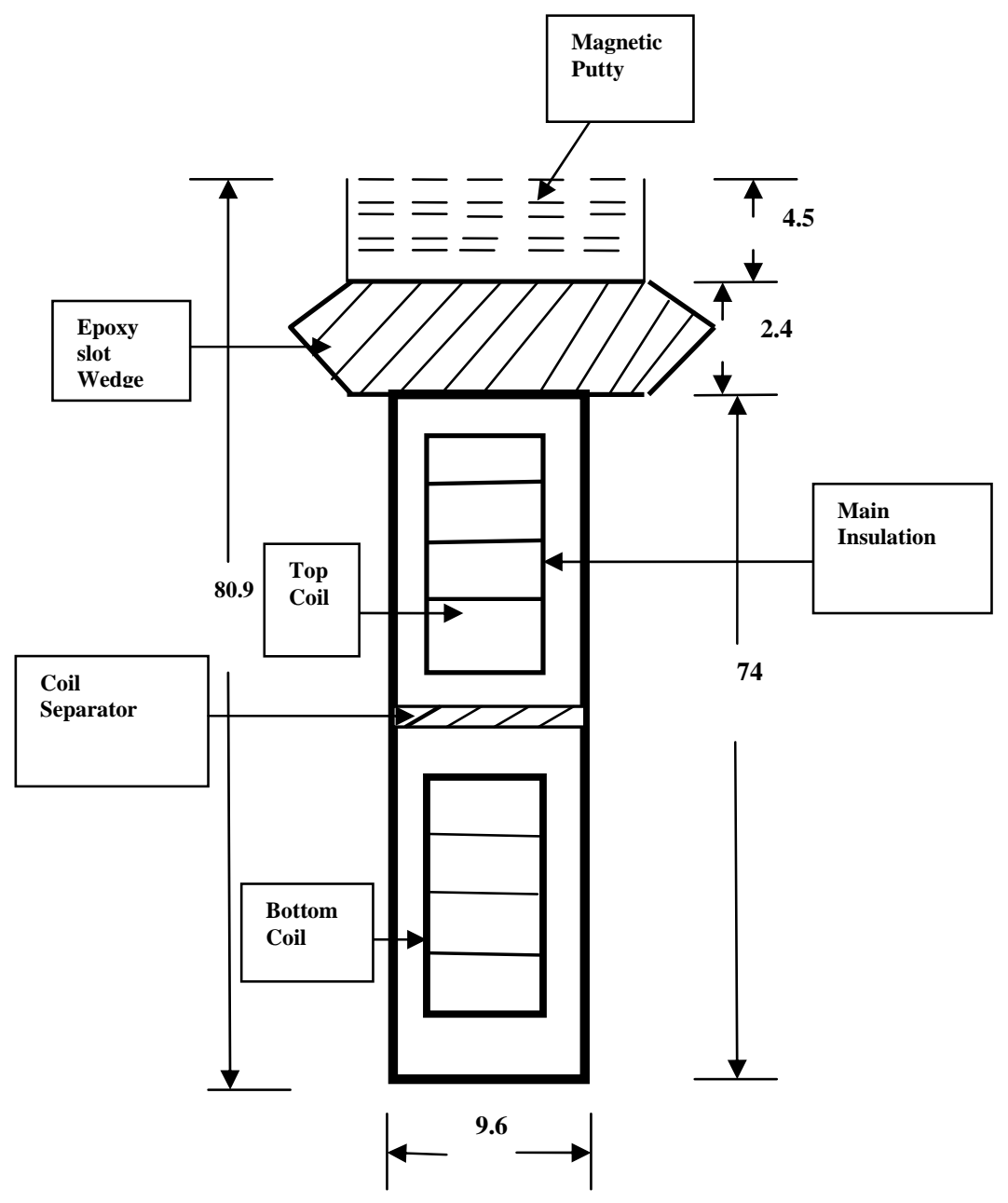

Figure 1. Design view of stator coil profile for 970KW Ex e HT induction motor

\subsection{Number of Stator Slots}

To ensure a satisfactory performance of the motor, number of stator slots per pole per phase is kept three for $810 \mathrm{KW}$ and $970 \mathrm{KW}$ and nine for $2200 \mathrm{KW}$ motor. A large number of stator slots reduces the leakage reactance due to reduction in slot and zigzag leakage thus giving more output per volume, more breakdown torque, somewhat better efficiency and power factor, reduced harmonics and less chances of cogging and crawling and reduced magnetic noise. Magnetic noise levels can be reduced by adjusting various motor design parameters such as stator-rotor slot dimension and numbers [18].

\subsection{Area of Stator Slot and Teeth}

The stator slot dimensions are so adjusted that the mean flux density in stator teeth should lie between 1.4 to $1.9 \mathrm{~Wb} / \mathrm{M}^{2}$ as well as sufficient copper can be put to give optimum output in the particular frame size. The space factor for copper in slots is kept 0.4 , the advantage of this lower value is for these high voltage motors due to increased insulation thickness.

The stator slot width is $9.3 \mathrm{~mm}$ (for $810 \mathrm{KW}$ motor), $9.6 \mathrm{~mm}$ (for $970 \mathrm{KW}$ motor) and $18 \mathrm{~mm}$ (for $2200 \mathrm{KW}$ motor) and it is kept almost equal to teeth width. Similarly, the stator slot depth is so chosen that the ratio of slot depth to slot width should lie between 3.0 to 6.0. The dimension of the slots determine the mechanical feasibility and the lower value of flux density in teeth. A high value of flux density in teeth leads to higher iron loss, hot spot formation and high magnetizing current thus poor power factor. 


\subsection{Stator Core Depth}

The stator core depth is always kept equal or more than slot depth to ensure a rigid core with no hot spots due to excess flux density in core. Apart from the rigid core, more important points are considered for stator winding overhang and coil drop which may not go beyond stator outside diameter. Hence enough space has been left above winding overhang to ensure satisfactory assembly.

\section{Design of Stator Winding of Ex e Motor}

The stator winding is designed in such a way that it can sustain upto permissible limit of abnormal specified conditions. The stator winding is provided with temperature-independent devices to protect the motor against the effect of excessive winding heating due to overloads, increased ambient temperature, impaired cooling, intermittent switching frequency, and phase failure. The detail of stator winding for all above mentioned Ex e HT motors are as follows:

\subsection{Type of Coils / Winding}

These Ex motors are designed with double layer, wave type, diamond pulled, multi turn, star connected coils. The coil in double layer winding represents the entire set of conductors in one slot layer in association with similar set in other layer of another slot. The number of coils is therefore same as number of slots. The diamond pulled shape of coils ease the coil housing in slots and adequate bracing of the coil overhangs to minimize the effect of Electro-magnetic stresses. Star connected windings are used for three HT motors because with star connection, the phase voltages are $1 / \sqrt{ } 3$ of line voltages, hence corresponding insulation thickness is got reduced. The Triple frequency harmonics, those may be generated in three phase motors, are totally eliminated by using star connection.

\subsection{Area of Stator Conductor}

Rectangular cross section conductor is used for stator winding of these motors for better current density. The width to thickness ratio of rectangular conductors is within the limit between 2.5 to 3.5 .

\subsection{Stator Resistance}

The resistance of stator winding is fixed after finalizing the type of winding, length of mean turn, turns per phase and cross sectional area of conductor.

\subsection{Special Insulation System}

The motor stator winding is designed with the help of good quality of insulation system. The high voltage stator winding is composed of several insulating, conducting and semi conducting materials applied at proper locations for specific functions which can sustain high impulse voltage and cannot become source of ignition. The Resin Poor Vacuum Pressurized Impregnation (VPI) system is used for these HT Ex e motors. In this system, the bare copper conductor of winding is insulated with glass backed epoxy mica paper tape and glass backing material as carrier. The binder is used of epoxy resin with suitable accelerator that binds the mica and backing material together to provide sufficient turn insulation. Stack of the slot portion is consolidated in boat shape by curing epoxy polyester fleece with hot pressing on heated hydraulic press. Overhang and slot portion of the winding are then insulated with sufficient layers of accelerator containing resin poor mica tape. Slot corona protection and end corona protection are then applied with a suitable overlap. Overhang of the coils is finally provided with diffusion barrier tape to prevent the outflow of epoxy impregnate from the insulation. These insulated coils are then laid in the stator with suitable packing and brazing of series joints and pole to pole connections is done. The top of the slot is filled with hot curing magnetic putty which improves the efficiency and power factor. The complete stator capsule is then dipped in VPI tank containing epoxy impregnating resin and subsequently cured in oven to achieve proper electrical and mechanical properties of the completed stator winding. It helps to fill voids in the insulation and provides necessary electrical properties and discharge free insulation/winding. This insulation system has passed the test for ignition risk assessment. 


\subsection{Bracing of Stator Winding Overhang}

During the starting, the induction motor takes high value of inrush starting current which produce tremendous electromagnetic forces in the overhang portion of the stator winding. To take care of this, the overhang portion of stator winding is adequately braced /secured so as to withstand various radial / tangential forces experienced by it during each start of motor.

\section{Effect of Higher Stator Coil Pitch on Motor Design Parameters}

These motors are designed in such way that stator winding can sustain stator and rotor ignition risk assessment in explosive atmospheres as per requirement of IS/IEC 60079-7:2007. Table 1 shows the variation of design parameters of Ex e motor with increase in stator coil pitch from normal Ex e motor of same rating. The Table 2 shows the design parameters for stator coil pitch which is common for both kinds of designed motors.

Table 1. Change in designed parameters of normal Ex e motor and Ex e motor with change in coil profile

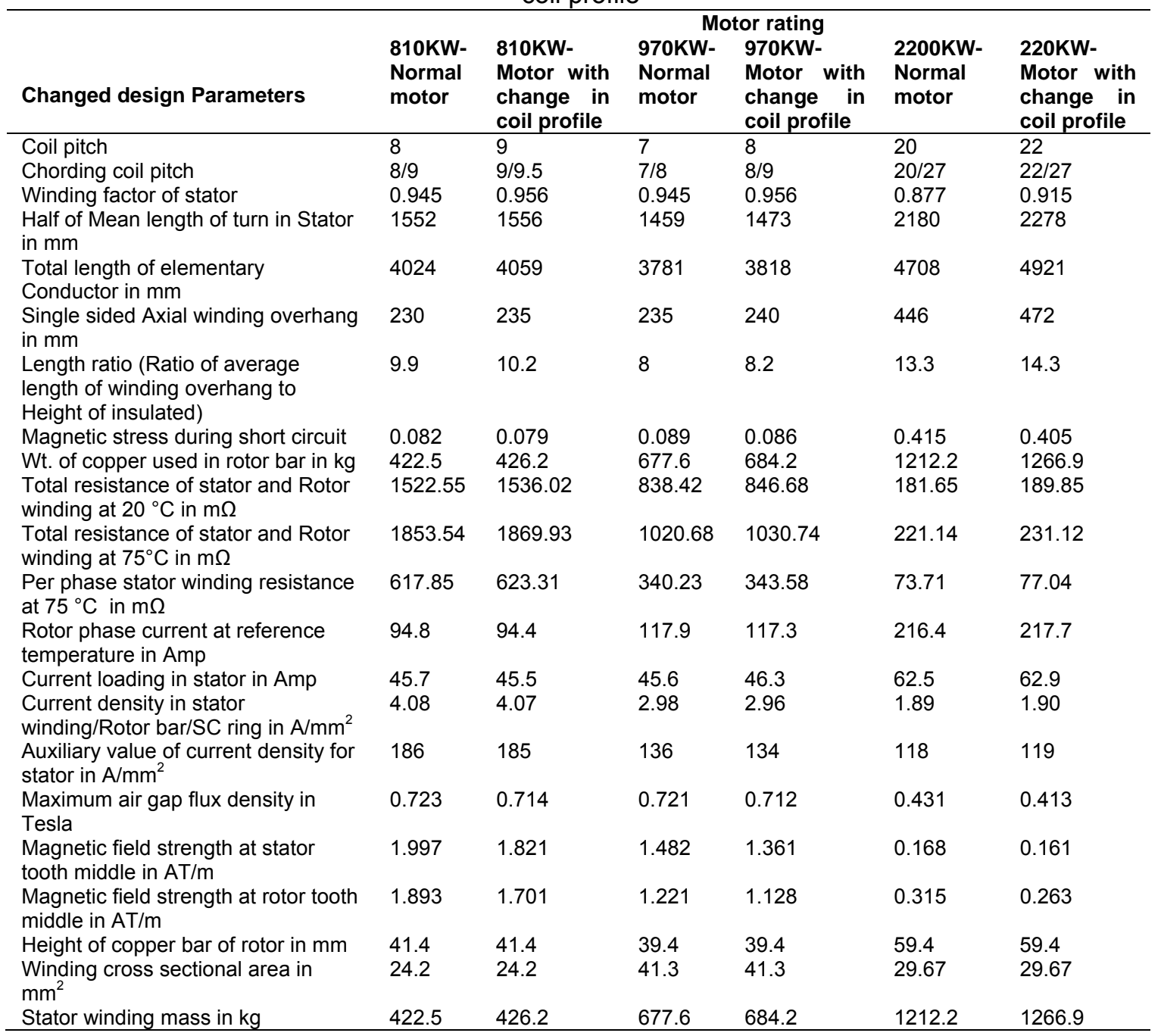


Table 2. Stator winding parameters for change in stator coil pitch

\begin{tabular}{llll}
\hline $\begin{array}{c}\text { Stator coil pitch design } \\
\text { parameters }\end{array}$ & $\begin{array}{c}\text { 810KW-Normal motor } \\
\text { and change in coil profile }\end{array}$ & $\begin{array}{c}\text { Motor rating } \\
\text { 970KW-Normal motor } \\
\text { and change in coil profile }\end{array}$ & $\begin{array}{c}\text { 2200KW- Normal motor } \\
\text { and change in coil profile }\end{array}$ \\
\hline No. of slot & 144 & 162 & 54 \\
pole & 16 & 18 & 2 \\
Slot/pole & 9 & 9 & 27 \\
phase & 3 & 3 & 3 \\
Slot/pole/phase & 3 & 3 & 9 \\
Conductor per slot & 18 & 16 & 20 \\
Parallel path & 2 & 2 & 2 \\
Slot pitch & 18.98 & 21.04 & 34.91 \\
Tooth width & 9.58 & 11.31 & 17.31 \\
\hline
\end{tabular}

\section{Design of Rotor of Ex e HT Motor}

\subsection{Design of Squirrel Cage Rotor}

The squirrel cage rotor is designed with insulated bars, made of copper, embedded in semi closed rotor slots. These bars are short circuited at both ends by short circuiting rings made of copper. The bars are brazed with SC rings by induction brazing for good electrical connection having sufficient mechanical strength.

\subsection{Number of Rotor Slots}

The selection of number of rotor slots is done based on the stator slots. The number of rotor slot and stator slot is not kept same to avoid peculiar behavior of motor when it is started like cogging, crawling and excessive noise. These undesirable characteristics are largely due to the harmonics present in air gap flux due to stator and rotor currents.

\subsection{Design of Rotor Cage}

The design of rotor cage consists of finding out bar and end ring dimension, resistances, profile of rotor slot and corresponding leakage reactance etc. The choice of rotor bar resistance is very important because as on one side high resistance of bar gives excellent starting performance (high starting torque and low starting current), while on other side the efficiency gets reduced due to increased copper losses.

\subsection{Rotor Bar Material, Size \& Shape}

The material and shape of the rotor bar govern the torque-speed characteristics and value of starting current drawn by the motor. The cross sectional area of rotor bar is considered on the basis of rotor bar current and current density for rotor bar. The rectangular rotor bar (for $810 \mathrm{KW}$ and $970 \mathrm{KW}$ motor) and trapezoidal rotor bar (for 2200KW motor) shapes with double cage construction of bars of copper/brass material are used for high starting torque with low starting current. The frequency of starts of motor, temperature rise per start and thermal withstand characteristics is considered during design of rotor.

\subsection{Rotor Radial Air Gap}

The air gap between stator and rotor is a very critical part which depends on the performance parameters of the motor like magnetizing current, power factor, overload capacity, cooling and noise. These performance parameters are affected by the length of air gap between stator and rotor. The air gap calculation for Ex e motor is different than ordinary induction motor. The radial air gap between stator and rotor of increased safety motor is very important for consideration during design to avoid sparking and arcing in the air gap at the end pockets of motors. The minimum air gap is calculated on the basis of equation (2).

$$
\text { Air gap }=\{0.15+[(D-50) / 780][0.25+(0.75 \times \mathrm{n} / 1000)]\} \text { ry [3] }
$$

Where,

$\mathrm{D}=$ rotor diameter in $\mathrm{mm}$ (subject to a minimum of $75 \mathrm{~mm}$ and a maximum of $750 \mathrm{~mm}$ )

$r=$ core length $/(1.75 \times \mathrm{D})$

$\mathrm{n}=$ maximum rated speed in RPM and $\mathrm{y}=1$ for motor with rolling bearing or 1.5 for plain bearing

IJEEI Vol. 2, No. 2, June 2014 : 63 - 75 
The rotor air gap was kept higher than the calculated value for Ex e motor. The designed radial air gap value is more than the calculated value as per the standard IS/IEC 60079-7. The radial air gap value of all Ex e motors under discussion is calculated by using equation (2). The value of different design parameters are tabulated in the Table 3.

Table 3. Radial air gap design parameters of Ex e motors

\begin{tabular}{cccccccc}
\hline $\begin{array}{c}\text { Motor } \\
\text { rating }\end{array}$ & $\begin{array}{c}\mathbf{D} \text { in } \\
\mathbf{m m}\end{array}$ & $\begin{array}{c}\text { n in } \\
\text { RPM }\end{array}$ & $\begin{array}{c}\text { Core length } \\
\text { in } \mathbf{~ m m}\end{array}$ & $\mathbf{y}$ & $\mathbf{r}$ & $\begin{array}{c}\text { Calculated Air gap as } \\
\text { per Eqn. (2) in } \mathbf{~ m m}\end{array}$ & $\begin{array}{c}\text { Maintained air gap in the } \\
\text { designed Ex e } \mathbf{m o t o r} \text { in } \mathbf{m m}\end{array}$ \\
\hline $810 \mathrm{KW}$ & 600 & 372 & 1036 & 1 & 0.986 & 0.515 & 1.8 \\
$970 \mathrm{KW}$ & 700 & 330 & 920 & 1 & 0.751 & 0.423 & 2.5 \\
$2200 \mathrm{KW}$ & 330 & 2970 & 862 & 1 & 1.490 & 1.545 & 5 \\
\hline
\end{tabular}

\section{Test on Motors}

The ignition risk assessment, high voltage test, locked rotor test (for measurement of rate of temperature rise for the stator and rotor, starting current ratio $I_{A} / I_{N}$ and time $t_{E}$ ), no load test, performance test/load test, temperature rise tests, vibration test, noise level test, test for ignition risk assessment and other relevant tests are conducted on the motors by using IEC 60034 and other relevant standards. The above motors have been tested as per standards and motors have fulfilled the requirement of standards. The details of the tests are not covered in this paper.

\section{Assessment and Calculation of Time $t_{E}$ of Rotor and Stator Winding of Ex e Motor}

The Ex e three phase induction HT motor rated 2200KW, 6.6KV, 2pole is chosen among the three ratings $810 \mathrm{KW}, 970 \mathrm{KW}$ and $2200 \mathrm{KW}$ for providing the details of assessment and calculation of important parameters of normal motors and with increase in coil pitch of stator. The temperature rise, time $t_{E}$ of rotor and stator winding, $I_{A} / I_{N}$ ratio etc. are calculated and assessed after conducting the relevant tests on all the aforesaid designed motors. The $\mathrm{F}$ class insulation is used in the winding of the aforesaid motors and calculation and assessment is done at insulation class $\mathrm{B}-10^{\circ} \mathrm{C}$ as per end user requirement. The detail of methodology for assessment and calculation is given below:

\subsection{Stator Winding Temperature Rise by Resistance Method of Normal Motor Under full Load Condition}

The cold resistance of stator winding and machine temperature was measured and recorded. Then motor was run for several hours at full load until thermal stabilization was attained. After thermal stabilization, the motor was then switched off and hot resistance of stator winding and ambient temperature was measured within the specified time and accordingly temperature rise of stator winding is calculated as per Eq. (3) [18].

$$
\text { Temperature rise }\left(T_{R}\right)=\left[\left(R_{\text {hot }}-R_{\text {cold }}\right) / R_{\text {cold }}\right] \times\left(235+t_{1}\right)+\left(t_{1}-t_{a}\right) \text {, }
$$

Where,

$\mathrm{R}_{\text {cold }}=$ Cold resistance of stator winding of motor in $\Omega=0.06407 \Omega$,

$R_{\text {hot }}=$ Hot resistance of stator winding of motor in $\Omega=0.0826 \Omega$,

$\mathrm{t}_{1}=$ Machine Temperature at the initial cold resistance measurement in ${ }^{\circ} \mathrm{C}=21^{\circ} \mathrm{C}$,

$\mathrm{t}_{\mathrm{a}}=$ Ambient temperature at the end of the examination corresponding to hot resistance in ${ }^{\circ} \mathrm{C},=30^{\circ} \mathrm{C}$,

Temperature rise $\left(T_{R}\right)=[(0.0826-0.06407) / 0.06407] \times(235+21)+(21-30)=64.99^{\circ} \mathrm{C}$.

\subsection{The Time $t_{E}$ for Stator of Normal 2200KW Ex e Motor}

$$
\text { Rate of temperature rise: } \Delta \theta / t_{E}=a \times j^{2} \times b,
$$

Where,

$\Delta \theta=$ Temperature difference between limiting temperature and Total temperature determined by resistance method in ${ }^{\circ} \mathrm{C}$, 
Total temperature $(T)=$ Temperature rise determined by resistance method $\left(T_{R}\right)+$ Ambient temperature $\left(T_{A}\right)$

$\mathrm{a}=0.0065$ for copper ${ }^{\circ} \mathrm{C} /\left(\mathrm{A} / \mathrm{mm}^{2}\right)^{2}$ sec.

$b=0.85$ reduction factor for heat dissipation,

$t_{E}=$ time in second,

$\mathrm{j}=$ Current density at starting in $\mathrm{A} / \mathrm{mm}^{2}$,

Hence, $t_{E}$ for stator is calculated as follows by using Eq. (4):

Starting Current of motor $=401.3 \mathrm{~A}$,

Winding copper cross sectional area $=29.67 \mathrm{~mm}^{2}$,

Insulation class of winding $=\mathrm{F}$,

Limiting temperature for stator with respect to class $\mathrm{F}$ insulation $=170^{\circ} \mathrm{C}$ (at ambient temp. $40^{\circ} \mathrm{C}$ limited to insulation class $\left.\mathrm{B}-10^{\circ} \mathrm{C}\right)[10]$,

Total temperature $(\mathrm{T})=\mathrm{T}_{\mathrm{R}}+\mathrm{T}_{\mathrm{A}}=64.99^{\circ} \mathrm{C}+40^{\circ} \mathrm{C}=104.99^{\circ} \mathrm{C}$,

Current density at starting $=401.3 / 29.67=13.52 \mathrm{~A} / \mathrm{mm}^{2}$,

$\Delta \theta=$ Limiting temperature $-\mathrm{T}$,

$=170-104.99=65.01^{\circ} \mathrm{C}$,

Rate of temperature rise $=\Delta \theta / t_{E}=a \times j^{2} \times b=0.0065 \times(13.52)^{2} \times 0.85=1.0^{\circ} \mathrm{C} / \mathrm{sec}$,

Time ' $t_{E}$ ' $=65.01 / 1.0=65.01 \mathrm{sec}$.

Hence the time ' $t_{E}$ ' for stator is 65.01 seconds.

\subsection{The Time $t_{E}$ for Rotor of Normal 2200KW Ex e Motor}

The cage rotor temperature rise of Ex e HT induction motor can be calculated with the help of Joules effect heat balance equation as given below:

$$
m \times s \times \Delta \theta=b \times I^{2} R \times t_{E},
$$

where,

$\mathrm{m}=$ mass of cage winding $=447.4 \mathrm{Kg}$,

$\mathrm{s}=$ specific heat of copper $=0.396$,

$\mathrm{b}=$ ventilation factor $=0.85$,

$\mathrm{I}^{2} \mathrm{R}=$ copper loss in rotor winding $=$ Starting torque $\times \mathrm{KW}$ of motor,

$=0.593 \times 2200 \mathrm{KW}$ (starting torque is $59.3 \%$ of rated torque),

$\Delta \theta=$ Maximum allowable temperature (T3 class) - Maximum rated operating temperature (for insulation Class $B)$,

$\Delta \theta=(200-120)^{\circ} \mathrm{C}=80^{\circ} \mathrm{C}$,

By putting the above values in the Eq. (5),

$\mathrm{t}_{\mathrm{E}}=\{(447.4 \times 0.396 \times 80) /(0.85 \times 0.593 \times 2200)\}$,

$=12.78 \mathrm{sec}$.

The time $t_{E}$ for rotor is $12.78 \mathrm{sec}$.

\section{Time $t_{E}$ of Rotor and Stator Winding of 2200kw Ex e Motor with Increase in Coil Pitch}

\subsection{Estimated Temperature Rise of the Motor under Full Load Condition with Change in Coil Pitch}

Temperature rise $=($ New effective loss $/$ Existing effective loss $) \times($ Existing surface area

/ New surface area) $\times T_{R}$

Effective loss of motor $=0.45$ core loss + stator copper loss +0.3 rotor copper loss

So effective losses of $2200 \mathrm{KW} / 6.6 \mathrm{KV} / 18$ pole normal motor based on Eq. (7) is

$=0.45 \times 6.83+10.53+0.3 \times 23.06=20.51 \mathrm{KW}$,

Similarly the effective losses of motor when coil pitch is increased is

$=0.45 \times 6.28+11.13+0.3 \times 25.48=21.60 \mathrm{KW}$,

As the surface area of the motor is not changed and it remains same in both the design of Ex $e$ motors and the estimated temperature rise of the motor as per Eq. (6) with change in coil pitch is; 
Temperature rise $=($ New effective loss $/$ Existing effective loss $) \times T_{R}$, $=21.60 / 20.15 \times 64.99=69.66^{\circ} \mathrm{C}$.

\subsection{The time $t_{E}$ for stator of $2200 \mathrm{KW}$ motor with increase in stator coil pitch}

Rate of Temperature rise as per Eq. (4): $\Delta \theta / t_{E}=a \times j^{2} \times b$,

Where,

$\Delta \Theta=$ Temperature difference between limiting temperature and total temperature determined by resistance method in ${ }^{\circ} \mathrm{C}$,

$\mathrm{a}=0.0065$ for copper ${ }^{\circ} \mathrm{C} /\left(\mathrm{A} / \mathrm{mm}^{2}\right)^{2}$.sec.

$b=0.85$ reduction factor for heat dissipation,

$t_{E}=$ time in second,

$\mathrm{j}=$ Current density at starting in $\mathrm{A} / \mathrm{mm}^{2}$,

Hence $t_{E}$ is calculated as follows by using Eq. (4):

Starting Current of motor $=373.8 \mathrm{~A}$,

Winding copper cross section area $=29.67 \mathrm{~mm}^{2}$,

Insulation class of winding $=\mathrm{F}$,

Limiting temperature for stator with respect to class $\mathrm{F}$ insulation $=170^{\circ} \mathrm{C}$ (at ambient temp. $40^{\circ} \mathrm{C}$ limited to insulation class $\mathrm{B}-10^{\circ} \mathrm{C}$ ),

Total temperature $=$ Estimated temperature rise + Ambient temperature,

$=69.66{ }^{\circ} \mathrm{C}+40^{\circ} \mathrm{C}=109.66^{\circ} \mathrm{C}$,

Current density at starting, $\mathrm{j}=373.8 / 29.67=12.59 \mathrm{~A} / \mathrm{mm}^{2}$,

$\Delta \theta=$ Limiting temperature - Total Temp determined by resistance method $=170-109.66=$ $60.34^{\circ} \mathrm{C}$

Rate of temperature rise $=\Delta \theta / t_{E}=0.0065 \times(12.59)^{2} \times 0.85=0.87^{\circ} \mathrm{C} / \mathrm{sec}$.

Time ' $t_{E}$ ' $=60.34 / 0.87=69.35$ seconds.

Hence, calculated time ' $\mathrm{t}_{\mathrm{E}}$ ' for stator $=69.35$ seconds.

\subsection{The Time $t_{E}$ for Rotor of $2200 K W$ Motor with Increase in Stator Coil Pitch}

The cage rotor temperature rise of Ex e HT motor can be calculated with help of Joules effect heat balance equation as per Eq. (5) as given below:

$\mathrm{m} \times \mathrm{s} \times \Delta \theta=\mathrm{b} \times \mathrm{I}^{2} \mathrm{R} \times \mathrm{t}_{\mathrm{E}}$,

where,

$\mathrm{m}=$ mass of cage winding $=447.40 \mathrm{Kg}$,

$\mathrm{s}=$ specific heat of copper $=0.396$,

$\mathrm{b}=$ ventilation factor $=0.85$,

$\mathrm{I}^{2} \mathrm{R}=$ copper loss in rotor winding = starting torque $\times \mathrm{KW}$ of motor,

$=0.566 \times 2200 \mathrm{KW}$ (starting torque is $56.6 \%$ of rated torque),

$\Delta \theta=$ Maximum allowable temperature (T3 class) - Maximum rated operating temperature (for

Class B),

$\Delta \theta=(200-120)^{\circ} \mathrm{C}=80^{\circ} \mathrm{C}$,

By putting the above values in the Eq. (4),

$t_{E}=\{(447.4 \times 0.396 \times 80) /(0.85 \times 0.566 \times 2200)\}=13.39$ seconds.

The time $t_{E}$ for rotor winding of Ex e motor with change in stator coil pitch is 13.39 seconds. As the time $t_{E}$ for rotor and stator is $12.78 \mathrm{sec}$ and $65.01 \mathrm{sec}$ respectively for normal motor and similarly the time $t_{E}$ for rotor and stator is $13.39 \mathrm{sec}$ and 69.39 seconds respectively for same rating of motor with increase in stator coil pitch, hence the declared time $t_{E}$ for motor will be 13.39 seconds.

Similarly the temperature rise, time $t_{E}$ for stator, time $t_{E}$ for rotor, $I_{A} / I_{N}$ ratio and other parameters of normal Ex e induction motors of rating $970 \mathrm{KW}$ and $2200 \mathrm{KW}$ and same Ex e induction motor with change in stator coil pitch of same rating of motor are also determined by using above methodology. All the designed and calculated parameters of Ex e induction motors are shown in the Table 4. 
Table 4. Performance parameters of Ex e normal motor and Ex e motor with change in coil pitch

\begin{tabular}{|c|c|c|c|c|c|c|}
\hline \multirow{2}{*}{$\begin{array}{l}\text { Performance } \\
\text { Parameters }\end{array}$} & \multicolumn{6}{|c|}{ Motor rating } \\
\hline & $\begin{array}{l}\text { 810KW- } \\
\text { Normal } \\
\text { motor }\end{array}$ & $\begin{array}{l}\text { 810KW- } \\
\text { Motor with } \\
\text { increase in } \\
\text { coil pitch }\end{array}$ & $\begin{array}{l}\text { 970KW- } \\
\text { Normal } \\
\text { motor }\end{array}$ & $\begin{array}{l}970 \mathrm{KW}-\text { Motor } \\
\text { with increase in } \\
\text { coil pitch }\end{array}$ & $\begin{array}{l}\text { 2200KW- } \\
\text { Normal motor }\end{array}$ & $\begin{array}{l}220 \mathrm{KW} \text { - Motor } \\
\text { with increase in } \\
\text { coil pitch }\end{array}$ \\
\hline $\begin{array}{l}\text { Temperature rise at } \\
\text { full load }\end{array}$ & $37.49^{\circ} \mathrm{C}$ & $37.49^{\circ} \mathrm{C}$ & $44.13^{\circ} \mathrm{C}$ & $44^{\circ} \mathrm{C}$ & $64.99^{\circ} \mathrm{C}$ & $69.66^{\circ} \mathrm{C}$ \\
\hline Time $t_{E}$ for stator & $31.79 \mathrm{sec}$ & $34.64 \mathrm{sec}$ & $89.44 \mathrm{sec}$ & $97.72 \mathrm{sec}$ & $65.01 \mathrm{sec}$ & $69.35 \mathrm{sec}$ \\
\hline Time $t_{E}$ for rotor & $18.67 \mathrm{sec}$ & $20.05 \mathrm{sec}$ & $16.77 \mathrm{sec}$ & $18.04 \mathrm{sec}$ & $12.78 \mathrm{sec}$ & $13.39 \mathrm{sec}$ \\
\hline $\begin{array}{l}\text { Time } t_{E} \text { for tripping } \\
\text { device of Ex e } \\
\text { motor }\end{array}$ & $\leq 18.67 \mathrm{sec}$ & $\leq 20.05 \mathrm{sec}$ & $\leq 16.77 \mathrm{sec}$ & $\leq 18.04 \mathrm{sec}$ & $\leq 12.78 \mathrm{sec}$ & $\leq 13.39 \mathrm{sec}$ \\
\hline $\begin{array}{l}\text { Ratio Starting } \\
\text { current/rated } \\
\text { current }\left(\mathrm{I}_{\mathrm{A}} / \mathrm{I}_{\mathrm{N}}\right)\end{array}$ & 5.73 & 5.49 & 4.23 & 4.06 & 2.22 & 2.07 \\
\hline
\end{tabular}

\section{Performance Analysis of Ex e Induction Motor with Increase in Stator Coil Pitch}

The performance analysis of each Ex e induction motor with increase stator coil pitch is done by comparing it with the normal Ex e induction motor of same rating. It has been observed that starting torque, core losses at no load, speed at full load, starting current and current density decreases but time $t_{E}$ of stator, time $t_{E}$ of rotor, power factor and full load slip increases. The efficiency and temperature rise of the motors with increase in stator coil pitch is remaining more or less same. The percentage values of variation of different parameters are shown in the Table 5.

Table 5. Performance analysis of Ex e induction motor with change in stator coil pitch

\begin{tabular}{|c|c|c|c|}
\hline $\begin{array}{l}\text { Performance analysis parameters } \\
\text { with change in coil pitch }\end{array}$ & $\begin{array}{l}\text { 810KW Motor with } \\
\text { increase in coil pitch }\end{array}$ & $\begin{array}{l}\text { 970KW Motor with } \\
\text { increase in coil pitch }\end{array}$ & $\begin{array}{l}\text { 2200KW Motor with } \\
\text { increase in coil pitch }\end{array}$ \\
\hline Increase/Decrease of temperature rise & $0 \%$ & $0.29 \%$ decrease & $7.18 \%$ increase \\
\hline Increase of time $t_{E}$ of rotor & $7.39 \%$ & $7.57 \%$ & $4.77 \%$ \\
\hline Decrease in current density & $4.45 \%$ & $4.09 \%$ & $7.38 \%$ \\
\hline Decrease/Increase in efficiency & $0 \%$ & $0 \%$ & $0.10 \%$ decrease \\
\hline Decrease in starting current & $4.43 \%$ & $4.04 \%$ & $7.35 \%$ \\
\hline Decrease in stator copper losses & $0.17 \%$ & $0 \%$ & $5.69 \%$ \\
\hline Increase in core losses at no load & $2.57 \%$ & $2.45 \%$ & $8.75 \%$ \\
\hline $\begin{array}{l}\text { Increase in losses (Core losses at no } \\
\text { load+ Stator copper losses at full load+ } \\
\text { Rotor copper losses at full load) }\end{array}$ & $0.09 \%$ & $0.02 \%$ & $6.1 \%$ \\
\hline
\end{tabular}

The Table 5 shows the effect of change in stator coil pitch on stator winding mass, stator copper loss and time $t_{E}$ of rotor and stator and $I_{A} / I_{N}$ ratio of Ex e induction motor. The $I_{A} / I_{N}$ ratio decreased and time $t_{E}$ has increased by increasing stator coil pitch which is good for Ex $e$ motor. It also shows that time $t_{E}$ of lower speed motors (810KW and $\left.970 \mathrm{KW}\right)$ has increased and it is more than higher speed motor $(2200 \mathrm{KW})$, similarly, $I_{A} / I_{N}$ ratio of lower speed motors (810KW and $970 \mathrm{KW}$ ) has decreased and it is less than higher speed motor (2200KW).

The $I_{A} / I_{N}$ ratio, time $t_{E}$ and air gap are very important parameters for any increased safety motors which is directly related with the safety of Ex e motor in the hazardous area. The graphical presentation of all above mentioned Ex e motors for time $t_{E}$ and $I_{A} / I_{N}$ ratio are shown in the Figure 2. The stator air gap was kept at slightly higher than the upper limit of ordinary design value for Ex e motor and the air gap is maintained same in both the cases. The stator air gap value of all Ex e motors under discussion is given in the Table 3 . The values of $I_{A} / I_{N}$ ratio, time $t_{E}$ and air gap for designed Ex e motor with increased coil pitch are more than the specified value in the IS/IEC 60079-7 standard.

IJEEI Vol. 2, No. 2, June 2014: $63-75$ 
It is also seen from the data of the Table 6 that efficiency and power factor is slightly varied as load increased for all the above mentioned Ex e motors.

Table 6. Load, efficiency and power factor parameters of normal Ex e motor and Ex e motor with increase in stator coil pitch

\begin{tabular}{|c|c|c|c|c|c|c|c|c|c|c|c|c|}
\hline \multirow[t]{2}{*}{$\begin{array}{l}\text { Load } \\
\%\end{array}$} & \multicolumn{2}{|c|}{$\begin{array}{l}\text { 810KW-Normal } \\
\text { motor }\end{array}$} & \multicolumn{2}{|c|}{$\begin{array}{l}810 \mathrm{KW} \text {-Motor } \\
\text { with increase in } \\
\text { coil pitch }\end{array}$} & \multicolumn{2}{|c|}{$\begin{array}{l}\text { 970KW-Normal } \\
\text { motor }\end{array}$} & \multicolumn{2}{|c|}{$\begin{array}{l}970 \mathrm{KW}-\text { Motor } \\
\text { with increase in } \\
\text { coil pitch }\end{array}$} & \multicolumn{2}{|c|}{$\begin{array}{l}2200 \mathrm{KW}- \\
\text { Normal motor }\end{array}$} & \multicolumn{2}{|c|}{$\begin{array}{l}2200 K W-\text { Motor } \\
\text { with increase in } \\
\text { coil pitch }\end{array}$} \\
\hline & $\begin{array}{c}\text { Efficiency } \\
\%\end{array}$ & p.f. & $\begin{array}{c}\text { Efficiency } \\
\%\end{array}$ & p.f. & $\begin{array}{c}\text { Efficiency } \\
\%\end{array}$ & p.f. & $\begin{array}{c}\text { Efficiency } \\
\%\end{array}$ & p.f. & $\begin{array}{c}\text { Efficiency } \\
\%\end{array}$ & p.f. & $\begin{array}{c}\text { Efficiency } \\
\%\end{array}$ & p.f. \\
\hline 25 & 92.07 & 38.1 & 92.28 & 0.392 & 91.9 & 33.3 & 92.12 & 0.341 & 91.83 & 87 & 91.90 & 0.887 \\
\hline 50 & 94.98 & 60.9 & 95.07 & 0.620 & 95 & 55.3 & 95.17 & 0.563 & 95.09 & 93 & 95.09 & 0.934 \\
\hline 75 & 95.51 & 72.1 & 95.55 & 0.727 & 95.8 & 67.6 & 95.84 & 0.683 & 95.91 & 93.2 & 95.86 & 0.932 \\
\hline 100 & 95.38 & 77.1 & 95.38 & 0.774 & 95.9 & 73.9 & 95.86 & 0.742 & 96.03 & 91.9 & 95.93 & 0.914 \\
\hline 125 & 95.51 & 0.746 & 95.54 & 0.751 & 95.88 & 0.706 & 95.90 & 0.712 & 95.79 & 0.892 & 95.59 & 0.881 \\
\hline
\end{tabular}

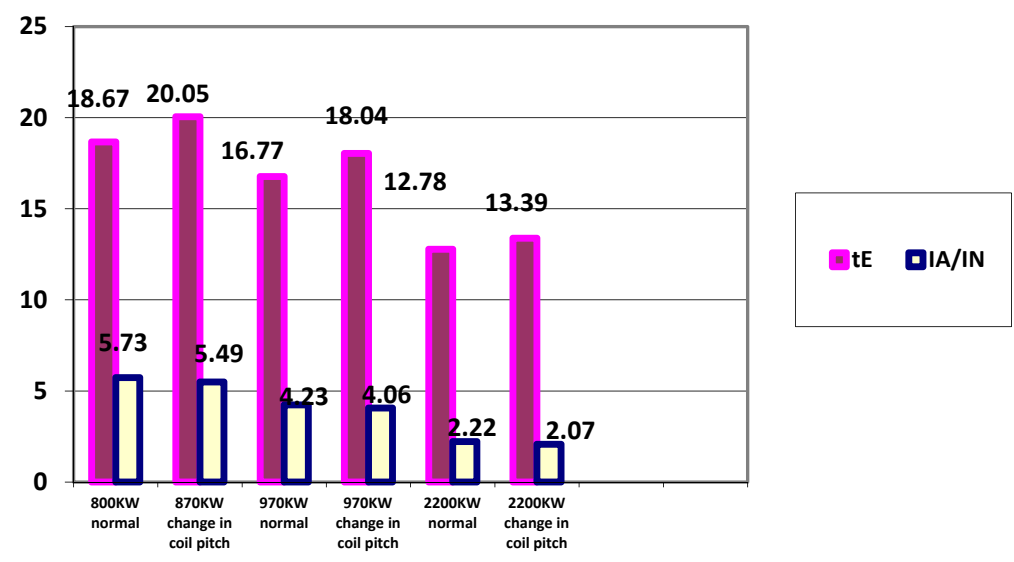

Figure 2. $I_{A} / I_{N}$ value with respect to Motor $t_{E}$ value of all Ex e designed motor and standards value

\section{Conclusions}

Increased safety of squirrel cage induction motor is necessary to avoid explosion hazard for its application in oil mines, coal mines, oil refineries, and petrochemical industries. Temperature rise of motor due to overloading, arc/spark of motor windings, high starting current or blocked rotor condition are very important conditions for safe operation of increased safety Ex e squirrel cage induction motor in hazardous area.

The paper describes the design aspect of squirrel cage induction motor for increased safety. The aim of this paper is to increase of time $t_{E}$ of motor. Increase of time $t_{E}$ of motor enhance the safety aspect of motor operation in explosive atmosphere. The protective relay/device of the motor would be getting sufficient time for switching off of power supply of motor during any abnormal specified condition of the motor which will cause high temperature rise. As temperature rise of the motor would be limited and less then the ignition temperature of the surrounding explosive atmosphere because of switching off of power supply by the protective relay/device. The motor operation in hazardous area would be more safe.

The study reveals that time $t_{E}$ of motor is increased by increasing the stator coil pitch of motor with increased safety features for all three motors. It has also been observed that the $I_{A} / I_{N}$ ratio of the motor has been decreased considerably and performance characteristics of the motor have also been improved for all the three motors. The designed Ex e HT induction motors are mentioned in this papers are running successfully at the different locations of the oil sector in the India. 


\section{Acknowledgement}

The authors are grateful to Dr. A. Sinha, Director, CSIR-CIMFR, Dhanbad for his kind permission to publish this technical research paper and also wish to record sincere thanks to the Dr. AK Singh, Senior Principal Scientist \& Head of Flame and Explosion Lab., CIMFR, Mr. SR Prasad, Executive Director, BHEL, Mr. B. Sonwane, Dy. General Manager, BHEL, and Mr. Nisheet Khare, Dy. General Manager, BHEL, Bhopal for providing necessary help in carrying out this research work.

\section{References}

[1] IS 5571. Guide for selection and installation of electrical equipment in hazardous area (other than mines). Bureau of Indian Standards (BIS). 2009.

[2] IS/IEC 60079-0. Electrical apparatus for explosive gas atmospheres-General requirements. Bureau of Indian Standards (BIS). 2004.

[3] IS/IEC 60079-7. Electrical apparatus for explosive gas atmospheres- Increased safety. Bureau of Indian Standards (BIS). 2006.

[4] J Bredthauer; LB McClung and Tretzack H. Risk of Ignition due to Transition Currents in Medium Voltage Motors for Classified Locations. IEEE Transactions on Industry Application. 2002; 27(6): 1195-1203.

[5] J Bredthauer and N Struck. Starting of Large Medium Voltage Motor: Design, Protection and Safety Aspects. IEEE Transactions on Industry Application. 1995; 31(5): 1167-1176.

[6] JH Dymond; N Stranges; K Younsi; and JE Hayward. Stator Winding Failures: Contamination, Surface Discharge and Tracking. IEEE Transactions on Industry Application. 2002; 38(2): 577-582.

[7] R Ong; JH Dymond and B Mistry. Design of increased safety electrical machine: Development activities and certification testing. IEEE PCIC Conference. 2000: 65-75.

[8] P Clark; G Neville and R Regan. Solutions for MV motors and generators in hazardous locations. International Conference PCIC-96. 1996: 61-73.

[9] K Padden; Rick, Bried, and James, H Dymond, Lorraine. Instructional overview of IEEE 1349-2001Guide for the Application of Electric Motors in Class I, Division 2 Hazardous (Classified) Locations. IEEE Transactions on Industry Applications. 2005; 41(1): 101-111.

[10] Jussi, Rautee; Frank, Lienesch and Tom, Liew. Safety improvements of non-sparking and increased safety motors. Fifth IEEE PCIC-Electrical and Instrumentation Application. 2008: 1-9.

[11] Dirk, Arnold and Vladimir, Barinberg. Explosion protected electrical machines with type of protection "e" and " $n A$ " Requirements, Risk Analysis, Type tests, Conclusions. Proceedings of the IEEE 2008 International Conference on Electrical Machines. 2008; Paper ID 816, 1-4.

[12] Hee-Dong, Kim and Tae-Sik, Kong. Assessment of insulation deterioration in stator winding of high voltage motor. The transactions of the Korean Institute of Electrical Engineers. 2012; 61(5): 711-716.

[13] Bhagirath, Ahirwal; TK Chatterjee. Design, ignition risk assessment and testing of increased safety HT induction motor for explosive atmospheres. IET Electric Power Applications. 2013; 7(5): 1-8.

[14] Bharat, Mistry; William, G Lawrence; Evans, Massey, and Paul, S Hamer. Proposed revisions to IEC 60079-15 how has harmonization affected Ex nA motors? IEEE PCIC Conference -Europe. 2009: 2127.

[15] B Mistry; WG Lawrence; R Bulgarelli and F Lienesch. Motors of explosive gas atmosphere: Selectioninstallation-inspection-maintenance following IEC standards. Proceedings of Petroleum and Chemical Industry Conference- Europe. 2012: 1-9.

[16] Colin, Grantham. Electrical Machines and Drives for Potentially Explosive Atmospheres. Journal of International Conference on Electrical Machines and Systems. 2012; 1(1): 128-134.

[17] B Ahirwal; AK Singh; RK Vishwakarma and A Sinha. Increased Safety Protection and Energy Conservation for Motors installed in Zone 1 \& 2 Hazardous area using variable Speed drives (VSDs). International Journal of COMADEM. 2009; 12: 15-23.

[18] Radu, S Curiac and Sumit, Singhal. Magnetic noise in induction motors. Proceeding of NCAD2008. 2008: $1-5$.

IJEEI Vol. 2, No. 2, June 2014 : 63 - 75 